\title{
Optimization of E. coli Tip-Sonication for High-Yield Cell Free Extract using Finite Element Modeling
}

\author{
Md Sakib Ferdous ${ }^{1}$, Jared Dopp ${ }^{1}$, and Nigel Reuel ${ }^{1}$ \\ ${ }^{1}$ Iowa State University of Science and Technology
}

May 6, 2021

\begin{abstract}
Optimal tip sonication settings, namely tip position, input power, and pulse durations, are necessary for temperature sensitive procedures like preparation of viable cell extract. In this paper, the optimum tip immersion depth (20-30\% height below the liquid surface) is estimated which ensures maximum mixing thereby enhancing thermal dissipation of local cavitation hotspots. A finite element (FE) heat transfer model is presented, validated experimentally with ( $\mathrm{R} 2>97 \%$ ) and used to observe the effect of temperature rise on cell extract performance of E. coli BL21 DE3 star strain and estimate the temperature threshold. Relative yields in the top $10 \%$ are observed for solution temperatures maintained below $32^{\circ} \mathrm{C}$; this reduces below $50 \%$ relative yield at temperatures above $47^{\circ} \mathrm{C}$. A generalized workflow for direct simulation using the COMSOL code as well as master plots for estimation of sonication parameters (power input and pulse settings) is also presented.
\end{abstract}

\section{Hosted file}

for submission to AICHE_-_..pdf available at https://authorea.com/users/398739/articles/ 520932-optimization-of-e-coli-tip-sonication-for-high-yield-cell-free-extract-usingfinite-element-modeling 